\title{
Prognostic factors and survival according to tumour subtype in women presenting with breast cancer bone metastases at initial diagnosis: a SEER-based study
}

Xiao Li ${ }^{1}$, Xiaoli Zhang ${ }^{2}$, Jie Liu² and Yinzhong Shen ${ }^{1,3^{*}}$

\begin{abstract}
Background: Tumour subtype has a significant effect on bone metastasis in breast cancer, but population-based estimates of the prognosis of patients with bone metastases at breast cancer diagnosis are lacking. The aim of this study was to analyse the influence of tumour subtype and other factors on the prognosis and survival of patients with bone metastases of breast cancer.

Methods: Using the Surveillance, Epidemiology, and End Results (SEER) Program data from 2012 to 2016, a retrospective cohort study was conducted to investigate stage IV breast cancer patients with bone metastases. Stage IV patient characteristics according to subtype were compared using chi-square tests. Overall survival (OS) and prognostic factors were compared using the Kaplan-Meier method and the Cox proportional hazards model, respectively.

Results: A total of 3384 stage IV patients were included in this study; $63.42 \%$ were HR+/HER2-, 19.86\% were HR+/ HER2+, 9.34\% were HR-/HER2-, and 7.39\% were HR-/HER2+. The median OS for the whole population was 38 months, and $33.9 \%$ of the patients were alive at 5 years. The median OS and five-year survival rate were significantly different among stage IV breast cancer patients with different molecular subtypes $(p<0.05)$. Multivariate Cox regression analysis showed that age of 55-59 $(H R=1.270)$, black race $(H R=1.317)$, grade III or IV $(H R=1.960)$, HR-/HER2- $(H R=2.808)$, lung metastases ( $H R=1.378)$, liver metastases $(H R=2.085)$, and brain metastases $(H R=1.903)$ were independent risk factors for prognosis; married status $(H R=0.819), H R+/ H E R 2+(H R=0.631), H R-/ H E R 2+(H R=0.716)$, insurance $(H R=0.587)$ and surgery $(H R=0.504)$ were independent protection factors of prognosis. There was an interaction between the HR+/ HER2+ subtype and other metastases (except bone metastases, HR=0.694, 95\% Cl: 0.485-0.992), but the interaction between race and subtype did not reach significance for prognosis.

Conclusions: There were substantial differences in OS according to tumour subtype. In addition to tumour subtype, other independent predictors of OS were age at diagnosis, race, marital status, insurance, grade, surgery and visceral metastases. There was an interaction between the HR+/HER2+ subtype and other metastases (except bone metastases) for prognosis. Tumour subtype, as a significant prognostic factor, warrants further investigation.
\end{abstract}

Keywords: Breast cancer, Bone metastases, Tumour subtype, Prognostic factor, Survival

\footnotetext{
* Correspondence: shenyinzhong@shphc.org.cn

'Department of Medical Affairs, Shanghai Public Health Clinical Center, Fudan University, Shanghai, China

${ }^{3}$ Department of Infection and Immunity, Shanghai Public Health Clinical Center, Fudan University, Shanghai, China

Full list of author information is available at the end of the article
}

(C) The Author(s). 2020 Open Access This article is licensed under a Creative Commons Attribution 4.0 International License, which permits use, sharing, adaptation, distribution and reproduction in any medium or format, as long as you give appropriate credit to the original author(s) and the source, provide a link to the Creative Commons licence, and indicate if changes were made. The images or other third party material in this article are included in the article's Creative Commons. licence, unless indicated otherwise in a credit line to the material. If material is not included in the article's Creative Commons licence and your intended use is not permitted by statutory regulation or exceeds the permitted use, you will need to obtain permission directly from the copyright holder. To view a copy of this licence, visit http://creativecommons.org/licenses/by/4.0/. The Creative Commons Public Domain Dedication waiver (http://creativecommons.org/publicdomain/zero/1.0/) applies to the data made available in this article, unless otherwise stated in a credit line to the data. 


\section{Background}

Breast cancer is the second most common type of cancer in women and the second leading cause of cancerrelated death in women. In these patients, it is not the primary tumour but its metastases at distant sites that are the main cause of death [1]. Approximately 5-10\% of patients have distant metastases at the time of diagnosis $[2,3]$. Bone is the most common site of metastasis in breast cancer patients, and more than $55 \%$ of breast cancer patients develop bone metastases [4]. Bone metastases are associated with lower survival in patients with advanced breast cancer [5]. A study showed that patients with breast cancer survive a median of 22-57.6 months after the detection of bone metastases [6-8]. Breast cancer patients with bone metastases seem to have a longer survival than those with cancer in other metastatic sites [9].

According to the classification by hormone receptor status and human epidermal growth factor receptor-2 (HER2), breast cancer can be divided into $\mathrm{HR}+1$ HER2-, HR+/HER2+, HR-/HER2- and HR-/HER2+ subtypes [10]. The strong association of hormone receptor status with bone metastasis was proposed in 1991 [11]. With a deeper understanding of the modulated genes and pathways in the various subgroups, it has become more evident that bone metastasis is most abundant among the hormonal receptor-positive subtypes [12]. Researchers have found that the clinical manifestations, pathological results, gene expression and prognosis of different subtypes of breast cancer are very different. The relationship between molecular subtype and the patterns of distant metastases has been documented. Evidence has shown that the risk of bone metastasis depends on the breast cancer subtype, and $\mathrm{HR}+$ patients are more likely to have bone metastases [13]. The molecular differences in tumour subtype are often accompanied by differences in clinical features and overall survival [10]. The distribution of molecular subtypes is different among breast cancer patients with different races, and race is a prognostic factor of breast cancer patients $[14,15]$. However, the effect of mixed race and subtype on prognosis has not been verified.

Notably, once a tumour metastasizes to the bone, it is incurable. Bone metastases are associated with lower survival in patients with advanced breast cancer and an increased risk of serious complications during the patient's disease course. The consequences of bone metastases include reduced survival, morbidity, pain and reduced quality of life [16]. Therefore, to improve the survival time and outcome of patients, identifying the influencing factors of clinical prognosis in breast cancer patients with bone metastasis has great significance. The aim of this study was to analyse the influence of tumour subtype and other factors on the prognosis and survival of patients who present with bone metastases at the time of initial diagnosis of breast cancer.

\section{Methods}

Data source and patient selection

We extracted data from the Surveillance, Epidemiology, and End Results (SEER) 18 registry research database. The SEER database of the National Cancer Institute is a coordinated system of population-based cancer registries that collects cancer incidence and survival data from 18 geographic areas throughout the United States that together represent approximately $28 \%$ of the U.S. population and includes various diverse ethnic groups. A data use agreement submission was required to access the SEER Research Data File [17]. We submitted the data agreement form to the SEER administration. After acceptance of the agreement, SEER ${ }^{*}$ Stat Version 8.3.5 software and data files were downloaded directly from the SEER website.

We used SEER ${ }^{*}$ Stat version 8.3.5 to generate a case listing. We extracted cases of women aged 40-60 with bone metastases of breast cancer diagnosed with a known breast subtype. Because the SEER database began collecting information on the HER2 status and sites of distant metastasis in 2010, the most recent edition of The SEER Cancer Statistics Review (CSR) (1975-2016) was released in April 2019. We explored the situation of breast cancer patients in the past 5 years, including women aged 40-60 diagnosed between 2010 and 2013 and selected this age group of women because the incidence of breast cancer increases over the age of 50, the natural mortality of elderly patients is high, and age is the second most important risk factor at primary diagnosis [18].

Patients diagnosed by either autopsy or death certificate were excluded. Patients must have complete dates of survival months and the follow-up must be active. The analysis was restricted to patients with a diagnosis confirmed by histopathology, and only duct, lobular and other carcinomas based on the primary site were included (International Classification of Diseases for Oncology, Third Edition (ICD-O-3) codes 8500 to 8543 ). Tumour stage was registered according to the AJCC staging system sixth edition.

We generated a case listing with information on the following variables: year of diagnosis, age at diagnosis, race/ethnicity, marital status at diagnosis, grade, laterality, ICD-O-3 Hist/behav, American Joint Committee on Cancer (AJCC) stage group 6th edition, surgery primary site, bone/lung/liver/brain metastases, tumour subtype, cause-specific death classification, vital status, and survival (months). Race was classified as white, black or 
other. Marital status was categorized as married, single (including never married, divorced, separated, and widowed) or other. Insurance was classified as uninsured, insured (including any Medicaid, insured, and insured-no specifics) or unknown. Because stage was suggested to be the most powerful prognostic factor in other studies and in the clinic and because stage IV patients exhibit worse survival rates than stage I-III patients, we only selected stage IV patients according to the AJCC stage group 6th edition.

\section{Statistical analysis}

Descriptive statistics were used to examine the following baseline characteristics of stage IV breast cancer patients with bone metastases: year of diagnosis, age, race/ethnicity, insurance, marital status, grade, surgery, laterality, histology, liver metastases, lung metastases, brain metastases, bone only metastases, BCSS (the time from breast cancer diagnosis to death due to breast cancer) and OS (the time from breast cancer diagnosis to death due to any cause). Age at diagnosis, race/ethnicity, insurance, marital status, grade, surgery, laterality, histology, liver metastases, lung metastases, brain metastases, and interaction terms between visceral metastases and subtype were used in the multivariate Cox model.

The variables were stratified by molecular subtype. $P$-values for comparing the frequency distributions among the subgroups were calculated using the chisquared $\left(x^{2}\right)$ test. For each variable, patients with unknown data were excluded from the comparative analysis. OS was the primary study outcome, and we used the Kaplan-Meier method to generate survival curves and analysed the differences between the curves using the log-rank test. A Cox proportional hazards regression model was used to assess the independent association of several variables with OS, and interaction analysis was performed by adding interaction items to the next layer. Hazard ratio (HR) and their 95\% confidence intervals (95\% CIs) were estimated using the Cox model. A $P$-value of 0.05 or less was considered statistically significant. All $P$-values were 2-tailed. All statistical analyses were performed using SAS version 9.2 (SAS Institute, Inc.) and IBM SPSS version 23.0.

\section{Results}

\section{Patient characteristics}

A total of 3384 stage IV patients were diagnosed with bone metastases from breast cancer at initial presentation between 2012 and 2016 and were included in this study. A total of 2146 stage IV patients $(63.41 \%)$ were diagnosed with HR+/HER2- breast cancer, 672 stage IV patients (19.86\%) were diagnosed with HR+/HER2+ breast cancer, 316 stage IV patients (9.34\%) were diagnosed with HR-/HER2- breast cancer, and 250 stage IV patients (7.39\%) were diagnosed with HR-/HER2+ breast cancer.

The demographic and clinical characteristics of the study participants based on breast cancer subtype are shown in Table 1. Stage IV patients with bone metastases from HR-/HER2- breast cancer were more likely to be white $(P<0.001)$. Patients with HR-/HER2-, HR+l HER2+ and HR-/HER2+ breast cancers were more likely to have higher tumour grades and a histological type classification of ductal carcinoma than those with HR+/HER2- breast cancer $(P<0.001)$. Visceral and only bone metastases were less frequent in HR+/HER2breast cancer patients $(P<0.001)$. HR-/HER2- breast cancer patients were more likely to die $(P<0.001)$.

\section{Survival analysis}

At a median follow-up of 17 months (range, 1-60 months), there were 1315 deaths $(60.53 \%$ in the $\mathrm{HR}+$ / HER2- group, $15.06 \%$ in the HR+/HER2+ group, $17.03 \%$ in the HR-/HER2- group and $7.38 \%$ in the HR-/HER2+ group).

The median OS for the entire population was 38 months (95\% CI: $35.89-40.11$ months), and $33.9 \%$ of the patients (95\% CI: 30.6-37.2\%) were alive at 60 months. Analysis of OS according to tumour subtype showed significant differences among stage IV patients with bone metastases, and the five-year survival rate was $32.7 \%$ for HR+/HER2- patients, $48.8 \%$ for HR+/HER2+ patients, $8.6 \%$ for HR-/HER2- patients and $36.1 \%$ for HR -/HER2+ patients. Stage IV HR-/HER2- breast cancer patients with bone metastases experienced the shortest survival (median OS: 11 months; 95\% CI: 9.9-12.1 months), whereas stage IV HR+/HER2+ breast cancer patients with bone metastases experienced the longest survival, with a median OS of 52 months (95\% CI was not estimable; $P<0.001)$. Shown in Fig. 1.

The impact of the presence of metastases at each individual site on OS is shown in Fig. 2. Stage IV patients with lung metastases (median OS: 23 months; 95\% CI: 19.98-26.02 months) had significantly shorter survival times than stage IV patients without lung metastases (median OS: 42 months; 95\% CI: 39.77-44.23 months; $P<0.001$; Fig. 2a). Stage IV patients with liver metastases (median OS: 22 months; 95\% CI: 19.10-24.86 months) had significantly shorter survival times than those without liver metastases (median OS: 44 months; 95\% CI: 41.14-46.86 months; $P<0.001$; Fig. 2b). Stage IV patients with brain metastases (median OS: 14 months; 95\% CI: $11.08-40.10$ months) had significantly shorter survival times than those without brain metastases (median OS: 40 months; 95\% CI: 37.80-42.20 months; $P<0.001$; Fig. 2c). A similar finding was seen for only bone metastases (median OS: 46 months; 95\% CI: 42.56- 
Table 1 Patient Characteristics According to Tumour Subtype

\begin{tabular}{|c|c|c|c|c|c|c|}
\hline Characteristics & $\begin{array}{l}\text { HR+/HER2- } \\
2146(63.41)\end{array}$ & $\begin{array}{l}\text { HR+/HER2+ } \\
672(19.86)\end{array}$ & $\begin{array}{l}\text { HR-/HER2- } \\
316(9.34)\end{array}$ & $\begin{array}{l}\text { HR-/HER2+ } \\
250(7.39)\end{array}$ & $\begin{array}{l}\text { Total } \\
3384(100)\end{array}$ & $\begin{array}{l}P- \\
\text { value }\end{array}$ \\
\hline Year of diagnosis & & & & & & 0.981 \\
\hline 2012 & $422(19.66)$ & 133(19.79) & $55(17.41)$ & $51(20.40)$ & $661(19.53)$ & \\
\hline 2013 & $441(20.55)$ & $138(20.54)$ & $68(21.52)$ & $52(20.80)$ & 699(20.66) & \\
\hline 2014 & $425(19.80)$ & 125(18.60) & $65(20.57)$ & $46(18.40)$ & 661(19.53) & \\
\hline 2015 & 428(19.94) & 143(21.28) & $59(18.67)$ & $45(18.00)$ & 675(19.95) & \\
\hline 2016 & $430(20.04)$ & 133(19.79) & $69(21.84)$ & $56(22.40)$ & 688(20.33) & \\
\hline Age at diagnosis & & & & & & 0.221 \\
\hline 40-44 years & 283(13.19) & 107(15.92) & $31(9.81)$ & $28(11.20)$ & $449(13.27)$ & \\
\hline 45-49years & $465(21.67)$ & 128(19.05) & $65(20.57)$ & $50(20.00)$ & 708(20.92) & \\
\hline $50-54$ years & 638(29.73) & $202(30.06)$ & $110(34.81)$ & $81(32.40)$ & $1031(30.47)$ & \\
\hline 55-59years & $760(35.41)$ & $235(34.97)$ & $110(34.81)$ & $91(36.40)$ & 1196(35.34) & \\
\hline Race & & & & & & $<0.001$ \\
\hline White & 1574(73.35) & $481(71.58)$ & 218(68.99) & $170(68.00)$ & $2443(72.19)$ & \\
\hline Black & $353(16.45)$ & 127(18.90) & $81(25.63)$ & $43(17.20)$ & $604(17.85)$ & \\
\hline Other ${ }^{a}$ & $211(9.83)$ & $64(9.52)$ & $16(5.06)$ & $33(13.20)$ & $324(9.57)$ & \\
\hline Unknown & $8(0.37)$ & $0(0.00)$ & $1(0.32)$ & $4(1.60)$ & 13(0.38) & \\
\hline Marital status & & & & & & 0.771 \\
\hline Single & $620(28.89)$ & 189(28.13) & $89(28.16)$ & $73(29.20)$ & $971(28.69)$ & \\
\hline Married & 1049(48.88) & $342(50.89)$ & $150(47.47)$ & 113(45.20) & 1654(48.88) & \\
\hline Other ${ }^{b}$ & $377(17.57)$ & $111(16.52)$ & $64(20.25)$ & $47(18.80)$ & $599(17.70)$ & \\
\hline Unknown & $100(4.66)$ & $30(4.46)$ & 13(4.11) & $17(6.80)$ & $160(4.73)$ & \\
\hline Insurance & & & & & & 0.490 \\
\hline Insured & 104(4.85) & $42(6.25)$ & 17(5.38) & $11(4.40)$ & 174(5.14) & \\
\hline Uninsured & 2027(94.45) & 623(92.71) & 297(93.99) & 235(94.00) & 3182(94.03) & \\
\hline Unknown & $15(0.70)$ & $7(1.04)$ & $2(0.63)$ & $4(1.60)$ & $28(0.83)$ & \\
\hline Grade & & & & & & $<0.001$ \\
\hline 1 & $247(11.51)$ & 21(3.13) & $4(1.27)$ & $2(0.80)$ & 274(8.10) & \\
\hline$\|$ & $1017(47.39)$ & $244(36.31)$ & $64(20.25)$ & $67(26.80)$ & 1392(41.13) & \\
\hline III or IV & $619(28.84)$ & $334(49.70)$ & $230(72.78)$ & 149(59.60) & 1332(39.36) & \\
\hline Unknown & $263(12.26)$ & 73(10.86) & 18(5.70) & $32(12.80)$ & $32(12.80)$ & \\
\hline Histology & & & & & & $<0.001$ \\
\hline Ductal & $1571(73.21)$ & 559(83.18) & $277(87.66)$ & $216(86.40)$ & $2623(77.51)$ & \\
\hline Lobular & $353(16.45)$ & $28(4.17)$ & 13(4.11) & $6(2.40)$ & $400(11.82)$ & \\
\hline Others & $222(10.34)$ & $85(12.65)$ & $26(8.23)$ & $28(11.20)$ & $361(10.67)$ & \\
\hline Laterality & & & & & & 0.153 \\
\hline Right & 1054(49.11) & $330(49.11)$ & 156(49.37) & $102(40.80)$ & $1642(48.52)$ & \\
\hline Left & 1070(49.86) & $337(50.15)$ & 155(49.05) & $146(58.40)$ & $1708(50.47)$ & \\
\hline Bilateral, single primary & $5(0.23)$ & $4(0.60)$ & $2(0.63)$ & $1(0.40)$ & $12(0.35)$ & \\
\hline Unknown & $17(0.79)$ & $1(0.15)$ & $3(0.95)$ & $1(0.40)$ & $22(0.65)$ & \\
\hline Lung metastases & & & & & & $<0.001$ \\
\hline No & $1643(76.56)$ & $452(67.26)$ & $216(68.35)$ & 158(63.20) & $2469(72.96)$ & \\
\hline Yes & $449(20.92)$ & 205(30.51) & $96(30.38)$ & $89(35.60)$ & $839(24.79)$ & \\
\hline Unknown & $54(2.52)$ & $15(2.23)$ & $4(1.27)$ & $3(1.20)$ & $76(2.25)$ & \\
\hline
\end{tabular}


Table 1 Patient Characteristics According to Tumour Subtype (Continued)

\begin{tabular}{|c|c|c|c|c|c|c|}
\hline Characteristics & $\begin{array}{l}\text { HR+/HER2- } \\
2146(63.41)\end{array}$ & $\begin{array}{l}\text { HR+/HER2+ } \\
672(19.86)\end{array}$ & $\begin{array}{l}\text { HR-/HER2- } \\
316(9.34)\end{array}$ & $\begin{array}{l}\text { HR-/HER2+ } \\
250(7.39)\end{array}$ & $\begin{array}{l}\text { Total } \\
3384(100)\end{array}$ & $\begin{array}{l}P \text { - } \\
\text { value }\end{array}$ \\
\hline Liver metastases & & & & & & $<0.001$ \\
\hline No & $1691(78.80)$ & $418(62.20)$ & 208(65.82) & 132(52.80) & $2449(72.37)$ & \\
\hline Yes & 423(19.71) & 244(36.31) & 101(31.96) & $155(46.00)$ & $883(26.09)$ & \\
\hline Unknown & $32(1.49)$ & 10(1.49) & $7(2.22)$ & $3(1.20)$ & $52(1.54)$ & \\
\hline Brain metastases & & & & & & $<0.001$ \\
\hline No & 1992(92.82) & 595(88.54) & 263(83.23) & 214(85.60) & $3064(90.54)$ & \\
\hline Yes & 107(4.99) & $62(9.23)$ & 44(13.92) & $31(12.40)$ & $244(7.21)$ & \\
\hline Unknown & $47(2.19)$ & $15(2.23)$ & $9(2.85)$ & $5(2.00)$ & $76(2.25)$ & \\
\hline Only bone metastases & & & & & & $<0.001$ \\
\hline No & $748(34.86)$ & $360(53.57)$ & $170(53.80)$ & $168(67.20)$ & $1446(42.73)$ & \\
\hline Yes & 1326(61.79) & $300(44.64)$ & $140(44.30)$ & $80(32.00)$ & 1846(54.55) & \\
\hline Unknown & $72(3.36)$ & $12(1.79)$ & $6(1.90)$ & $2(0.80)$ & $21(2.72)$ & \\
\hline Surgery & & & & & & 0.971 \\
\hline No & $1541(71.81)$ & 489(72.77) & $225(71.20)$ & 180(72.00) & 2435(71.96) & \\
\hline Yes & $588(27.40)$ & 179(26.64) & $88(27.85)$ & $68(27.20)$ & $923(27.28)$ & \\
\hline Unknown & $17(0.79)$ & $4(0.60)$ & $3(0.95)$ & $2(0.80)$ & $26(0.77)$ & \\
\hline Breast cancer -specific death & & & & & & $<0.001$ \\
\hline No & 1502(69.99) & $504(75.00)$ & 140(44.30) & $165(66.00)$ & $2311(68.29)$ & \\
\hline Yes & $644(30.01)$ & $168(25.00)$ & $176(55.70)$ & $85(34.00)$ & 1073(31.71) & \\
\hline Status & & & & & & $<0.001$ \\
\hline Alive & $1350(62.91)$ & 474(70.54) & $92(29.11)$ & 153(61.20) & 2069(61.14) & \\
\hline Dead & 796(37.09) & 198(29.46) & 224(70.89) & $97(38.80)$ & 1315(38.86) & \\
\hline
\end{tabular}

Other $^{\text {a }}$ (American Indian/AK Native, Asian/Pacific Islander)

Other $^{\text {b }}$ (divorced/widowed/separated)

Patients with unknown data were excluded from the comparative analysis.

49.44 months) compared with metastases to the bone and other sites (median OS: 24 months; 95\% CI: 24.6126.38 months $P<0.001$; Fig. 2d).

The unadjusted model results for the overall patient population were consistent with the log-rank analysis results (except laterality) and revealed that patients who were older, were black, were single, were uninsured, had ductal histology, had grade III or IV breast cancer, had primary bilateral breast cancer, had the triple-negative subtype, had visceral metastases and did not undergo surgery for the primary tumour had shorter OS (Table 2).

Multivariate Cox analyses confirmed that age of 55-59 (vs. age of 40-44, HR $=1.270,95 \%$ CI: $1.032-$ 1.562), black race (vs. white race, $\mathrm{HR}=1.317,95 \% \mathrm{CI}$ : $1.127-1.540$ ), grade III or IV (vs. grade I, HR $=1.960$, 95\% CI: 1.491-2.577), HR-/HER2- (vs. HR+/HER2-, $\mathrm{HR}=2.808$, 95\% CI: 2.169-3.634), lung metastases (vs. no lung metastases, $\mathrm{HR}=1.378,95 \% \mathrm{CI}: 1.188-1.598)$, liver metastases (vs. no liver metastases, $\mathrm{HR}=2.085$,
95\% CI: 1.795-2.422), brain metastases (vs. no brain metastases, $\mathrm{HR}=1.930,95 \% \mathrm{CI}: 1.542-2.248)$ were independent risk factors for prognosis; married status (vs. single status, $\mathrm{HR}=0.819,95 \% \mathrm{CI}$ : 0.707-0.949), insurance (vs. no insurance, $\mathrm{HR}=0.587,95 \% \mathrm{CI}$ : $0.459-0.751$ ) and surgery (vs. no surgery, $H R=0.504$, 95\% CI: $0.431-0.590)$ were independent protection factors of prognosis. There was an interaction between the HR+/HER2+ subtype and multi-metastases (bone +visceral metastases, $\mathrm{HR}=0.694,95 \% \mathrm{CI}$ : $0.485-0.992)$ on prognosis. Histology, primary laterality, and the interaction between race and subtype did not reach significance with this test. The multivariate Cox model is shown in Table 3.

\section{Discussion}

Bone metastases are the most common distant metastatic site in breast cancer, and severe complications, low quality of life, poor prognosis and significantly 


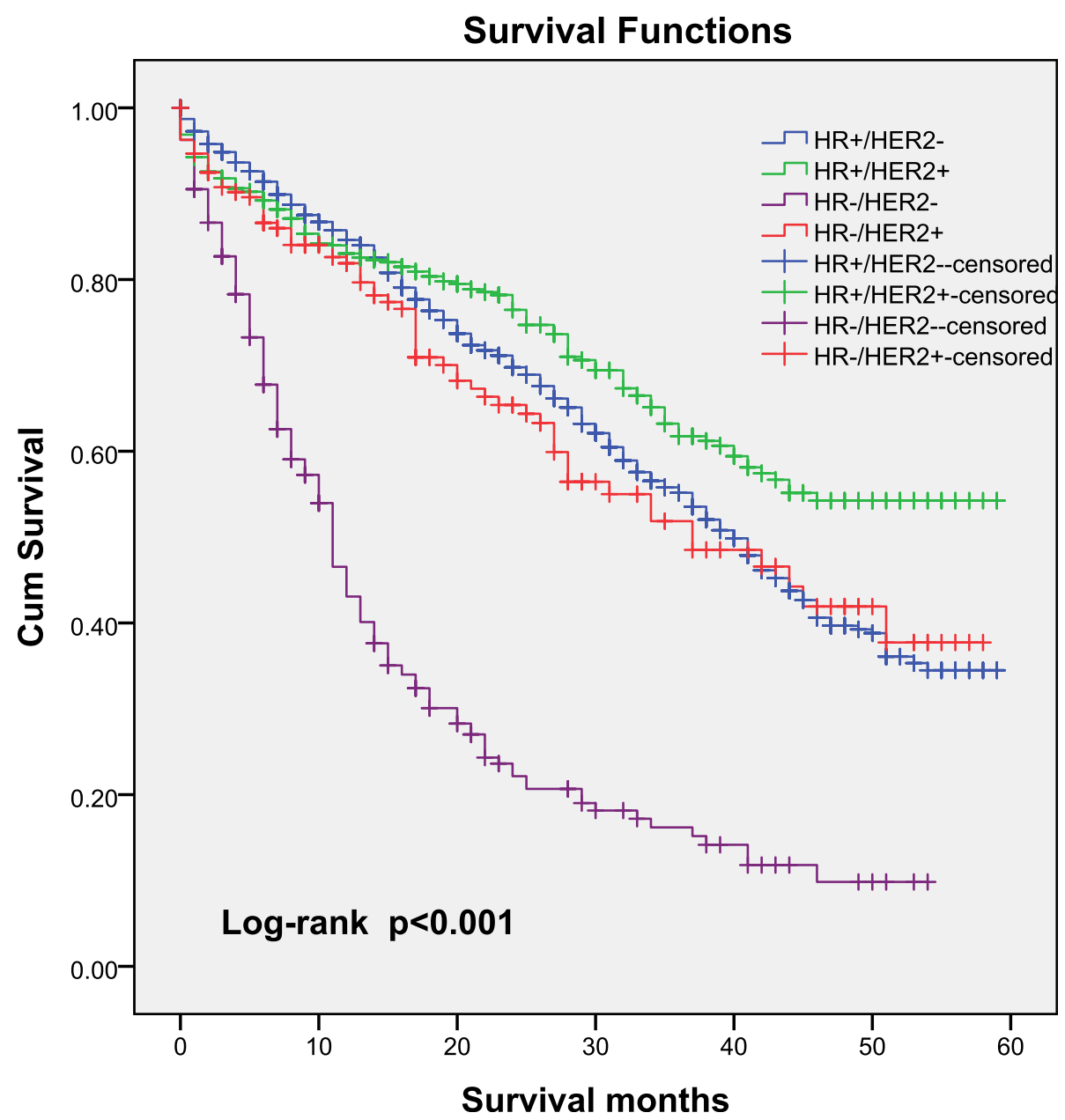

Fig. 1 Kaplan-Meier curve for overall survival according to tumour subtype

decreased survival rates are often associated with the occurrence of bone metastases [16]. Our study analysed recently available data on the subtypes of stage IV patients with bone metastatic breast cancer from the SEER registries in an attempt to analyse differences in the effects of the breast cancer subtype and other factors on patient prognosis.

Bone metastasis is most abundant among the HR+ subtypes, and the distribution of tumour subtypes in stage IV patients in our study was similar to that in other studies in the published literature $[12,19,20]$. Our study identified that stage IV patients with HR+/HER2breast cancer are the most prone to bone metastasis, followed by those with HR+/HER2+ breast cancer. HR -/HER2- breast cancer has a particular propensity to metastasize to the brain and lung; brain metastasis is more common in this subtype than in the other subtypes, and bone metastasis is relatively less likely to occur, which is consistent with the findings of previous research [21]. This may be due to the different molecular subtypes of breast cancer leading to different metastasis sites due to their special molecular biological characteristics.

The median OS for the entire cohort was 38 months, which is similar to that in Kuchuk's study, which reviewed 294 electronic records of metastatic breast cancer patients and found that the median OS from bone metastasis diagnosis was 40 months in bone metastasis patients [22]. The median OS was 46 months for stage IV patients with only bone metastases and 24 months for those with bone and other site metastases in our study, which was similar to the survival reported by previous authors in recent years [8]. A study of 815 patients with de novo or recurrent metastatic breast cancer identified that patients with visceral metastases and those with multiple metastatic sites had worse OS, findings consistent with our results [23]. The five-year survival rate was $33.9 \%$, 

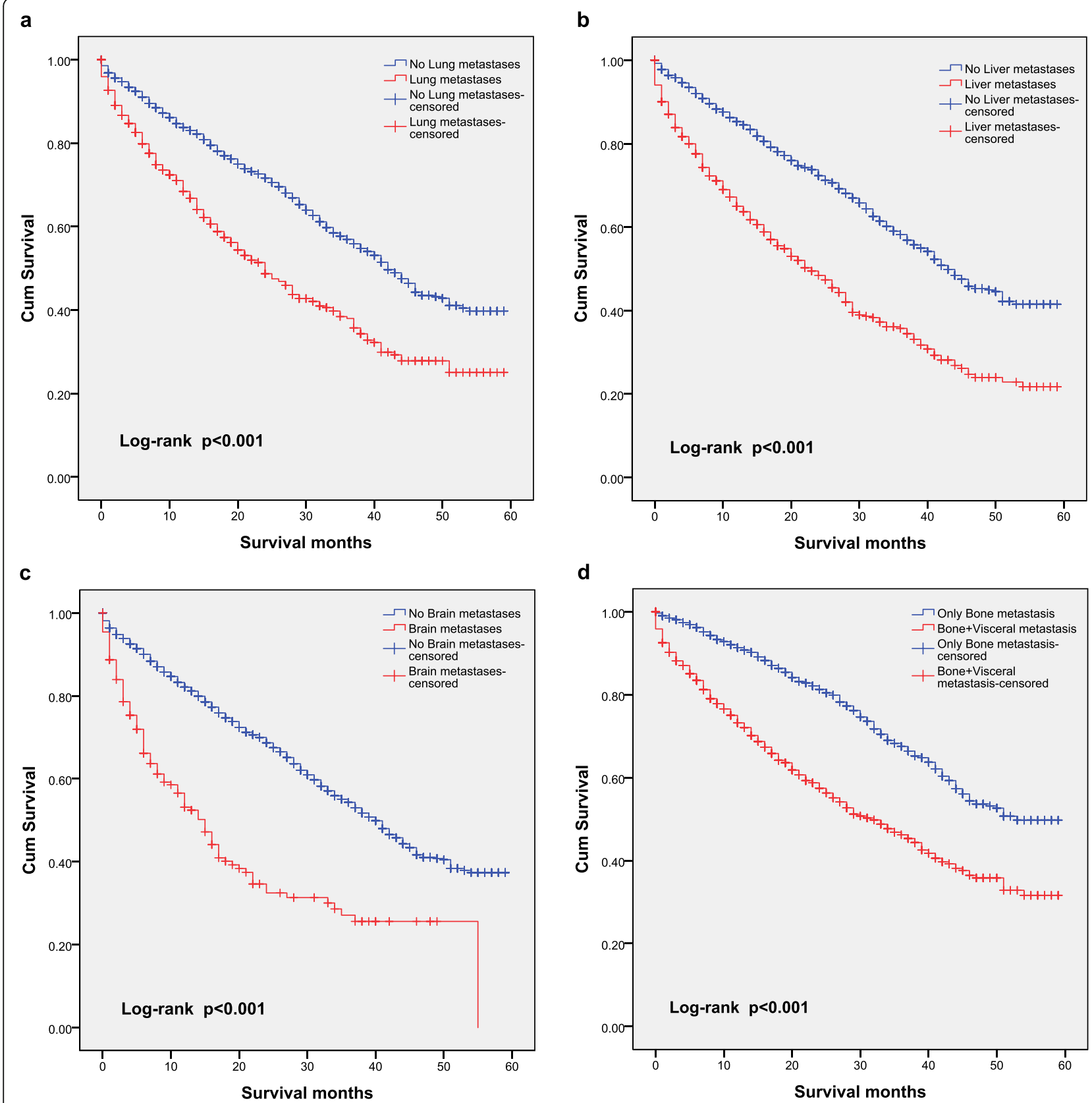

Fig. 2 Kaplan-Meier curves for overall survival according to the metastasis site

which is similar to that in previous studies, which showed that $24-39 \%$ of patients lived 5 years after the diagnosis of bone metastases [5]. This may be because the subjects of this study were menopausal women, while there was no limitation on the age of the previous study subjects; moreover, the proportion of elderly patients was large and their prognosis was poor, and with the improvement of treatment methods in recent years, the prognosis of patients has been improved.
Our study showed that the five-year survival rate of HR+/HER2 + stage IV patients was the highest, reaching 5.6 times that of HR-/HER2- patients. Stage IV patients with HR+/HER2+ breast cancer had the longest median survival period. Although our study showed that the incidence of bone metastasis in HR-/HER2- breast cancer patients was low, stage IV patients with HR-/HER2- tumours had the worst prognosis. With the shortest median survival time, the OS of stage IV patients with 
Table 2 Univariate analysis of prognostic factors

\begin{tabular}{|c|c|c|c|c|}
\hline Characteristics & Median OS & $P$ value & HR & $95 \% \mathrm{Cl}$ for $\mathrm{HR}$ \\
\hline Age at diagnosis & & $<0.001$ & & \\
\hline 40-44 years & 42 & & Reference & \\
\hline 45-49 years & 41 & & 1.013 & $0.829-1.237$ \\
\hline 50-54 years & 39 & & 1.103 & $0.915-1.329$ \\
\hline 55-59years & 32 & & 1.364 & $1.139-1.634$ \\
\hline Race & & $<0.001$ & & \\
\hline White & 41 & & Reference & \\
\hline Black & 28 & & 1.498 & $1.315-1.707$ \\
\hline Other ${ }^{a}$ & 38 & & 1.003 & $0.824-1.220$ \\
\hline Marital status & & $<0.001$ & & \\
\hline Single & 32 & & Reference & \\
\hline Married & 42 & & 0.723 & $0.638-0.819$ \\
\hline Other ${ }^{b}$ & 35 & & 0.903 & $0.772-1.057$ \\
\hline Insurance & & $<0.001$ & & \\
\hline Uninsured & 26 & & Reference & \\
\hline Insured & 38 & & 0.633 & $0.513-0.781$ \\
\hline Grade & & $<0.001$ & & \\
\hline I & 48 & & Reference & \\
\hline$\|$ & 44 & & 1.214 & $0.953-1.547$ \\
\hline III or IV & 28 & & 2.071 & $1.634-2.625$ \\
\hline Histology & & 0.003 & & \\
\hline Ductal & 36 & & Reference & \\
\hline Lobular & 44 & & 0.748 & $0.624-0.897$ \\
\hline Others & 40 & & 0.856 & $0.713-1.028$ \\
\hline Laterality & & 0.084 & & \\
\hline Right & 38 & & Reference & \\
\hline Left & 38 & & 1.058 & $0.949-1.179$ \\
\hline Bilateral, single primary & 13 & & 2.254 & $1.008-5.039$ \\
\hline Tumour subtype & & $<0.001$ & & \\
\hline $\mathrm{HR}+/ \mathrm{HER} 2-$ & 39 & & Reference & \\
\hline $\mathrm{HR}+/ \mathrm{HER} 2+$ & 52 & & 0.747 & $0.640-0.873$ \\
\hline HR-/HER2- & 11 & & 3.571 & $3.071-4.152$ \\
\hline HR-/HER2+ & 35 & & 1.132 & $0.917-1.397$ \\
\hline Bone+Lung metastases & & $<0.001$ & & \\
\hline No & 42 & & Reference & \\
\hline Yes & 23 & & 1.888 & $1.679-2.123$ \\
\hline Bone+Liver metastases & & $<0.001$ & & \\
\hline No & 44 & & Reference & \\
\hline Yes & 22 & & 2.182 & $1.950-2.443$ \\
\hline Bone+Brain metastases & & $<0.001$ & & \\
\hline No & 40 & & Reference & \\
\hline Yes & 14 & & 2.674 & $2.245-3.184$ \\
\hline Only bone metastases & & $<0.001$ & & \\
\hline No & 46 & & Reference & \\
\hline
\end{tabular}


Table 2 Univariate analysis of prognostic factors (Continued)

\begin{tabular}{|c|c|c|c|c|}
\hline Characteristics & Median OS & $P$ value & HR & $95 \% \mathrm{Cl}$ for $\mathrm{HR}$ \\
\hline Yes & 24 & & 2.29 & $2.04-2.559$ \\
\hline Surgery & & $<0.001$ & & \\
\hline No & 32 & & Reference & \\
\hline Yes & 52 & & 0.496 & $0.433-0.568$ \\
\hline
\end{tabular}

Other ${ }^{\text {a }}$ (American Indian/AK Native, Asian/Pacific Islander)

Other ${ }^{\mathrm{b}}$ (divorced/widowed/separated).

HR-/HER2- breast cancer was significantly lower than that of stage IV patients with other molecular subtypes. The large difference in prognosis observed across all tumour subtypes confirms that breast cancer is a heterogeneous disease, even in the specific group of patients with bone metastases. The improvements in OS seen in HER2+ patients could be explained in part by the efficacy of HER2-targeted agents. In Dawood's large-scale, randomized study of 2019 women with metastatic breast cancer, HER2+ patients who received trastuzumab had an improved prognosis compared with HER2- patients [24]. However, HR-/HER2- is an invasive subtype, with the characteristics of rapid progression, strong aggressiveness, a high degree of malignancy, easy occurrence of distant metastasis, and rapid relapse [25-27]. Therefore, our study included tumour subtype as a prognostic factor and provided evidence of a clear association of age, race, marital status, insurance, tumour grade, histology, subtype, and visceral metastases in bone metastasis patients with OS. This was similar to the findings of a previous study. The Denmark data were from population-based health registries that included all women diagnosed during 1999-2011 with regional or stage II/III breast cancer and showed predictors of recurrence, metastases, and mortality, including age, hormone receptor status, and stage at diagnosis [28]. Ahn's study showed that ERnegative status and bone metastasis combined with visceral metastasis are risk factors for OS [8]. Iqbal J's study showed that in US women diagnosed with invasive breast cancer, survival varies by race and ethnicity, and black women are more likely to die from breast cancer within 7 years than non-Hispanic white or Asian women [29]. A previous study observed that Hispanics and non-Hispanic blacks were more likely to have ER-positive and PR-negative tumours than non-Hispanic whites [30]. However, in our study, we found no interaction between subtype and race.

The protective effect of marriage on survival can be explained by these patients gaining better economic resources and having greater social support in marriage [31]. Although some factors have been found in previous studies, no covariates have been adjusted for other factors, or fewer covariates have been adjusted. We used a Cox proportional hazards regression model adjusting for all the factors, which demonstrated that tumour subtype was a prognostic factor. Therefore, in clinical and nursing work, doctors and nurses can carry out different treatments and nursing work for different patients according to age, race, marital status, insurance, tumour grade, histology, subtype, and visceral metastases. In addition, we found that there was an interaction between subtype and multiple visceral metastases, which suggests that we should pay attention to the risk of visceral metastasis in patients with different subtypes. Future studies are recommended to explore the mechanism of molecular subtype and metastasis site as well as the influence of their interaction on the outcome and management of patients.

We acknowledge that the study has some limitations. The SEER database does not provide information on the expression status of $\mathrm{Ki}-67$; the $\mathrm{Ki}-67$ index value is a prognostic factor in primary breast cancer and is a proliferation marker that also distinguishes between luminal $A$ and luminal B breast cancer [32]. Breast cancer is generally divided into luminal $\mathrm{A}$ and luminal $\mathrm{B}$ according to HR/HER2 status and Ki-67 in the course of clinical diagnosis and treatment [33]. This may contribute to some disparities between our investigation and clinical applications. We do not have information regarding the radiotherapy or systemic treatments of this cohort, which may contribute to some of the differences observed in survival according to prognostic variables. Additionally, the pathological data could not be centrally reviewed and were collected from different local pathology laboratories.

\section{Conclusion}

In conclusion, our results revealed a relatively good prognosis for stage IV patients with bone metastasis. The median OS was 38 months, and $33.9 \%$ of stage IV patients were alive at 5 years. Subtype was a significant prognostic factor, and the prognosis of stage IV patients 
Table 3 Multivariate analysis of prognostic factors

\begin{tabular}{|c|c|c|c|}
\hline Characteristics & $P$ value & HR & $95 \% \mathrm{Cl}$ for $\mathrm{HR}$ \\
\hline \multicolumn{4}{|l|}{ Age at diagnosis } \\
\hline 40-44 years & & Reference & \\
\hline 45-49 years & 0.542 & 0.932 & $0.741-1.170$ \\
\hline 50-54 years & 0.878 & 1.017 & $0.821-1.260$ \\
\hline $55-59$ years & 0.024 & 1.270 & $1.032-1.562$ \\
\hline \multicolumn{4}{|l|}{ Race } \\
\hline White & & Reference & \\
\hline Black & 0.001 & 1.317 & $1.127-1.540$ \\
\hline Other $^{\text {a }}$ & 0.128 & 1.192 & $0.951-1.495$ \\
\hline \multicolumn{4}{|l|}{ Marital status } \\
\hline Single & & Reference & \\
\hline Married & 0.008 & 0.819 & $0.707-0.949$ \\
\hline Other ${ }^{b}$ & 0.130 & 0.871 & $0.728-1.042$ \\
\hline Insurance (yes vs no) & $<0.001$ & 0.587 & $0.459-0.751$ \\
\hline \multicolumn{4}{|l|}{ Histology } \\
\hline Ductal & & Reference & \\
\hline Lobular & 0.744 & 1.041 & $0.820-1.321$ \\
\hline Others & 0.356 & 1.105 & $0.894-1.365$ \\
\hline \multicolumn{4}{|l|}{ Laterality } \\
\hline Right & & Reference & \\
\hline Left & 0.506 & 1.043 & $0.921-1.182$ \\
\hline Bilateral, single primary & 0.177 & 2.21 & $0.894-1.365$ \\
\hline \multicolumn{4}{|l|}{ Grade } \\
\hline I & & Reference & \\
\hline$\|$ & 0.309 & 1.147 & $0.881-1.492$ \\
\hline III or IV & $<0.001$ & 1.960 & $1.491-2.577$ \\
\hline \multicolumn{4}{|l|}{ Tumour subtype } \\
\hline HR+/HER2- & & Reference & \\
\hline $\mathrm{HR}+/ \mathrm{HER} 2+$ & 0.002 & 0.631 & $0.474-0.839$ \\
\hline HR-/HER2- & $<0.001$ & 2.808 & $2.169-3.634$ \\
\hline HR-/HER2+ & 0.258 & 0.716 & $0.401-1.277$ \\
\hline \multicolumn{4}{|l|}{ Site of metastases } \\
\hline Lung (yes vs no) & 0.020 & 1.378 & $1.188-1.598$ \\
\hline Liver (yes vs no) & $<0.001$ & 2.085 & $1.795-2.422$ \\
\hline Brain (yes vs no) & $<0.001$ & 1.903 & $1.542-2.248$ \\
\hline Surgery (yes vs no) & $<0.001$ & 0.504 & $0.431-0.590$ \\
\hline $\mathrm{HR}+/ \mathrm{HER} 2-{ }^{*}$ multi-metastases & & Reference & \\
\hline $\mathrm{HR}+/ \mathrm{HER} 2+{ }^{*}$ multi-metastases & 0.045 & 0.694 & $0.485-0.992$ \\
\hline HR-/HER2- * multi-metastases & 0.717 & 0.941 & $0.675-1.310$ \\
\hline HR-/HER2 $+{ }^{*}$ multi-metastases & 0.564 & 0.828 & $0.437-1.572$ \\
\hline \multicolumn{4}{|l|}{ Next step } \\
\hline White*HR+/HER2- & & Reference & \\
\hline Black*HR+/HER2+ & 0.366 & 0.821 & $0.536-1.258$ \\
\hline Other $a^{*} H R+/ H E R 2+$ & 0.652 & 0.862 & $0.453-1.641$ \\
\hline
\end{tabular}


Table 3 Multivariate analysis of prognostic factors (Continued)

\begin{tabular}{llll}
\hline Characteristics & $\boldsymbol{P}$ value & HR & $\mathbf{9 5 \%} \mathbf{C l}$ for HR \\
\hline Black*HR-/HER2- & 0.323 & 0.817 & $0.546-1.220$ \\
Other a*HR-/HER2- & 0.299 & 1.508 & $0.695-3.271$ \\
Black*HR-/HER2+ & 0.696 & 0.881 & $0.466-1.664$ \\
Other a*HR-/HER2+ & 0.368 & 0.701 & $0.323-1.521$ \\
\hline
\end{tabular}

Other ${ }^{\text {a }}$ (American Indian/AK Native, Asian/Pacific Islander)

Other ${ }^{\text {b }}$ (divorced/widowed/separated).

with the HR-/HER2- subtype was the worst, with a median OS of only 11 months. In addition to tumour subtype, race, marital status, insurance, grade, site of metastases, and surgery were independent predictors of OS. There was an interaction between subtype and multiple visceral metastases.

\section{Abbreviations}

OS: Overall survival; BCSS: Time from breast cancer diagnosis to death due to breast cancer; ER: Oestrogen receptor; PR: Progesterone receptor; HR-: ERand PR-; HR+: ER+ and/or PR+; HR: Hazard ratio; HER2: Human epidermal growth factor receptor-2; Cl: Confidence interval; ICD-O-3: International Classification of Diseases for Oncology, 3rd Edition

\section{Acknowledgements}

Not applicable.

\section{Authors' contributions}

$X \mathrm{~L}$, and $J \mathrm{~L}$ conceived the study design and analytical concept. $\mathrm{XL}$ conducted the data acquisition, performed the statistical analyses and drafted the manuscript. XLZ assisted with collection of meta data and interpretation. YZS participated in data interpretation, revision and supervision of manuscript. All authors contributed to the interpretation of the results and the critical revision of the manuscript. The authors participated in the revision of the manuscript and approved the final manuscript.

\section{Funding}

This work was supported by the Shanghai Municipal Key Clinical Specialty (No. Shslczdzk01102); the Ministry of Science and Technology of the People's Republic of China under the National Key Project of '13th Five-year' Infectious Diseases Program (No. 2017ZX10202101); and Fudan University under Grant No. RC-QT-2019-01. These funding bodies had no role in the study design, data collection, data interpretation, or writing of this manuscript.

\section{Availability of data and materials}

The datasets analyzed during the current study are available in the SEER repository (https://seer.cancer.gov/). The databases are public access.

\section{Ethics approval and consent to participate}

We received permission from the National Cancer Institute, US to access the research data file in the SEER program (reference number 13114-Nov2018). Ethics approval was not applicable because SEER data is publicly available and without specific identifiers.

\section{Consent for publication}

Not applicable.

\section{Competing interests}

The authors declare that they have no competing interests.

\section{Author details}

${ }^{1}$ Department of Medical Affairs, Shanghai Public Health Clinical Center, Fudan University, Shanghai, China. ${ }^{2}$ Department of Health Statistics, School of Public Health, China Medical University, Shenyang, China. ${ }^{3}$ Department of Infection and Immunity, Shanghai Public Health Clinical Center, Fudan University, Shanghai, China.
Received: 11 October 2019 Accepted: 30 October 2020

Published online: 13 November 2020

\section{References}

1. Surveillance Epidemiology, and end results program. Introduction to Breast Cancer https://www.training.seer.cancer.gov/breast/intro/. Accessed 9 July 2019

2. Kimbung S, Loman N, Hedenfalk I. Clinical and molecular complexity of breast cancer metastases. Semin Cancer Biol. 2015;35:85-95.

3. Yong $M$, Jensen $A O$, Jacobsen JB, Norgaard M, Fryzek JP, Sorensen HT Survival in breast cancer patients with bone metastases and skeletal-related events: a population-based cohort study in Denmark (1999-2007). Breast Cancer Res Treat. 2011;129(2):495-503.

4. Body JJ, Quinn G, Talbot S, Booth E, Demonty G, Taylor A, et al. Systematic review and meta-analysis on the proportion of patients with breast cancer who develop bone metastases. Crit Rev Oncol Hematol. 2017:115:67-80.

5. Lopez-Tarruella S, Escudero MJ, Pollan M, et al. Survival impact of primary tumor resection in de novo metastatic breast cancer patients (GEICAM/El Alamo registry). Sci Rep. 2019;9(1):20081 Published 2019 Dec 27.

6. Parkes $\mathrm{A}$, Warneke $\mathrm{CL}$, Clifton $\mathrm{K}$, et al. Prognostic factors in patients with metastatic breast cancer with bone-only metastases. Oncologist. 2018, 23(11):1282-8.

7. Terzi S, Trentin F, Carretta E, et al. Breast cancer spinal metastases: prognostic factors affecting survival after surgery. A retrospective study. J Clin Neurosci. 2020;78:73-8.

8. $\mathrm{Xu} \mathrm{B}, \mathrm{Hu}$ X, Feng J, et al. Chinese expert consensus on the clinical diagnosis and treatment of advanced breast cancer (2018). Cancer. 2020;126(Suppl 16):3867-82.

9. Wang Z, Chen M, Pan J, Wang X, Chen XS, Shen KW. Pattern of distant metastases in inflammatory breast cancer - a large-cohort retrospective study. J Cancer. 2020;11(2):292-300 Published 2020 Jan 1.

10. Sorlie T, Perou CM, Tibshirani R, Aas T, Geisler S, Johnsen H, et al. Gene expression patterns of breast carcinomas distinguish tumor subclasses with clinical implications. Proc Natl Acad Sci U S A. 2001;98(19):10869-74.

11. Koenders PG, Beex LV, Langens R, Kloppenborg PW, Smals AG, Benraad TJ. Steroid hormone receptor activity of primary human breast cancer and pattern of first metastasis. The breast cancer study group. Breast Cancer Res Treat. 1991;18(1):27-32.

12. Smid M, Wang Y, Zhang Y, Sieuwerts AM, Yu J, Klijn JG, et al. Subtypes of breast cancer show preferential site of relapse. Cancer Res. 2008;68(9):3108-14.

13. Tobin NP, Harrell JC, Lovrot J, Egyhazi BS, Frostvik SM, Carlsson L, et al. Molecular subtype and tumor characteristics of breast cancer metastases as assessed by gene expression significantly influence patient post-relapse survival. Ann Oncol. 2015;26(1):81-8.

14. Kohler BA, Sherman RL, Howlader N, Jemal A, Ryerson AB, Henry KA, et al. Annual report to the nation on the status of cancer, 1975-2011, featuring incidence of breast cancer subtypes by race/ethnicity, poverty, and state. $J$ Natl Cancer Inst. 2015;107(6):djv048.

15. Parada HJ, Sun X, Fleming JM, Williams-DeVane CR, Kirk EL, Olsson LT, et al. Race-associated biological differences among luminal a and basallike breast cancers in the Carolina breast cancer study. Breast Cancer Res. 2017;19(1):131.

16. Li BT, Wong MH, Pavlakis N. Treatment and prevention of bone metastases from breast cancer: a comprehensive review of evidence for clinical practice. J Clin Med. 2014;3(1):1-24. 
17. Surveillance, Epidemiology, and End Results Program. Data use agreement for the 1975-2016 SEER research data file. https:/seer.cancer.gov/data/ sample-dua.html. Accessed 12 July 2019.

18. Diessner J, Wischnewsky M, Stuber T, Stein R, Krockenberger M, Hausler S, et al. Evaluation of clinical parameters influencing the development of bone metastasis in breast cancer. BMC Cancer. 2016;16:307.

19. Leone BA, Vallejo CT, Romero AO, Machiavelli MR, Perez JE, Leone J, et al. Prognostic impact of metastatic pattern in stage IV breast cancer at initial diagnosis. Breast Cancer Res Treat. 2017;161(3):537-48.

20. Parkes A, Clifton K, Al-Awadhi A, Oke O, Warneke CL, Litton JK, et al. Characterization of bone only metastasis patients with respect to tumor subtypes. NPJ Breast Cancer. 2018;4:2.

21. Press DJ, Miller ME, Liederbach E, Yao K, Huo D. De novo metastasis in breast cancer: occurrence and overall survival stratified by molecular subtype. Clin Exp Metastasis. 2017;34(8):457-65.

22. Kuchuk I, Hutton B, Moretto P, Ng T, Addison CL, Clemons M. Incidence, consequences and treatment of bone metastases in breast cancer patientsexperience from a single cancer Centre. J Bone Oncol. 2013;2(4):137-44.

23. Lobbezoo DJ, van Kampen RJ, Voogd AC, Dercksen MW, van den Berkmortel F, Smilde TJ, et al. Prognosis of metastatic breast cancer: are there differences between patients with de novo and recurrent metastatic breast cancer? Br J Cancer. 2015;112(9):1445-51.

24. Dawood S, Broglio K, Buzdar AU, Hortobagyi GN, Giordano SH. Prognosis of women with metastatic breast cancer by HER2 status and trastuzumab treatment: an institutional-based review. J Clin Oncol. 2010;28(1):92-8.

25. Staaf J, Ringner M, Vallon-Christersson J, Jonsson G, Bendahl PO, Holm K et al. Identification of subtypes in human epidermal growth factor receptor 2--positive breast cancer reveals a gene signature prognostic of outcome. J Clin Oncol. 2010;28(11):1813-20.

26. Carey LA, Perou CM, Livasy CA, Dressler LG, Cowan D, Conway K, et al. Race, breast cancer subtypes, and survival in the Carolina breast cancer study. JAMA. 2006;295(21):2492-502.

27. Nguyen PL, Taghian AG, Katz MS, Niemierko A, Abi RR, Boon WL, et al. Breast cancer subtype approximated by estrogen receptor, progesterone receptor, and HER-2 is associated with local and distant recurrence after breast-conserving therapy. J Clin Oncol. 2008;26(14):2373-8.

28. Cronin-Fenton D, Kjaersgaard A, Norgaard M, Amelio J, Liede A, Hernandez RK, et al. Breast cancer recurrence, bone metastases, and visceral metastases in women with stage II and III breast cancer in Denmark. Breast Cancer Res Treat. 2018;167(2):517-28.

29. labal J, Ginsburg O, Rochon PA, Sun P, Narod SA. Differences in breast cancer stage at diagnosis and cancer-specific survival by race and ethnicity in the United States. JAMA. 2015;313(2):165-73.

30. Chavez-Macgregor M, Clarke CA, Lichtensztajn D, Hortobagyi GN, Giordano SH. Male breast cancer according to tumor subtype and race: a populationbased study. Cancer. 2013;119(9):1611-7.

31. Rendall MS, Weden MM, Favreault MM, Waldron $\mathrm{H}$. The protective effect of marriage for survival: a review and update. Demography. 2011;48(2):481506.

32. Nishimura R, Osako T, Nishiyama Y, Tashima R, Nakano M, Fujisue M, et al. Prognostic significance of $\mathrm{Ki}-67$ index value at the primary breast tumor in recurrent breast cancer. Mol Clin Oncol. 2014;2(6):1062-8,

33. Gnant M, Harbeck N, Thomssen C. St. Gallen/Nienna 2017: a brief summary of the consensus discussion about escalation and De-escalation of primary breast cancer treatment. Breast Care (Basel). 2017;12(2):102-7.

\section{Publisher's Note}

Springer Nature remains neutral with regard to jurisdictional claims in published maps and institutional affiliations.

Ready to submit your research? Choose BMC and benefit from:

- fast, convenient online submission

- thorough peer review by experienced researchers in your field

- rapid publication on acceptance

- support for research data, including large and complex data types

- gold Open Access which fosters wider collaboration and increased citations

- maximum visibility for your research: over $100 \mathrm{M}$ website views per year

At BMC, research is always in progress.

Learn more biomedcentral.com/submissions 